Tomomasa Kimura MD, Yukiko Goda MD, Osamu Kemmotsu MD PhD FCCM, Yasuhiro Shimada MD FCCP

\title{
Regional differences in skin blood flow and temperature during total spinal anaesthesia
}

Three patients were studied to determine the changes in regional skin temperature and blood flow during extensive sympathetic blockade following total spinal anaesthesia (TSA). Skin temperature was measured at the right upper arm, the right anterior chest at the nipple level, the right hand and the foot, using infrared thermography. Skin blood flow of the right upper arm (C6 area) was measured with a laser Doppler flowmeter. The temperature of the truncal area, arm and leg decreased by $1^{\circ} \mathrm{C}$ following TSA, whereas the temperature of the hand and foot increased by $3^{\circ} \mathrm{C}$. The mean blood flow in three patients decreased to $26.1,61.4,51.7 \%$ of the control values 15 min after TSA. Our results indicate that extensive sympathetic nervous blockade during total spinal anaesthesia induces regional different changes in skin temperature and decrease in truncal skin blood flow.

Trois patients ont été étudiés afin de déterminer les changements régionaux de la température cutanée et du débit sanguin, lors d'un bloc sympathique étendu, suite à une anesthésie sousarachnoidienne totale (TSA). La température a été mesurée à différentes sites, à l'aide de la thermographie à infrarouge : le bras droit supérieur, la surface antérieure droite du thorax au niveau du mamelon, ainsi que la main et le pied droits. Le débit sanguin cutané du bras droit supérieur (dermatome C6) a été mesuré à l'aide d'un débitmètre au lazer et utilisant le Doppler. La température de la surface thoracique, du bras et de la jambe a diminué de $1^{\circ} \mathrm{C}$ suite à la TSA, alors que la température de la

\section{Key words}

ANAESTHETIC TECHNIQUES: spinal;

MEASUREMENT TECHNIQUES: Doppler ultrasound; TEMPERATURE: body.

From the Department of Anesthesiology, Hokkaido University School of Medicine, Sapporo, Japan and Department of Anesthesiology, Nagoya University School of Medicine, Nagoya, Japan.

Address correspondence to: Dr. T. Kimura, Department of Anesthesiology, Nagoya University School of Medicine, Tsuruma-cho 65, Showa-ku, Nagoya, 466 Japan.

Accepted for publication 2nd October, 1991. main et du pied a augmenté de $3^{\circ} \mathrm{C}$. Le débit sanguin moyen chez les trois patientys a diminué de 26,1,61,4 et 51,7\% des valeurs de contrôle quinze minutes après la TSA. Nos résultats indiquent qu'un bloc nerveux sympathique étendu lors d'une anesthésie sous-arachnoïdienne totale provoque des changements régionaux différents au niveau de la température cutanée et dimine le débit sanguin cutané thoracique.

The level of sympathetic blockade during spinal anaesthesia may be detected using measurements of blood flow, temperature and skin galvanic response. ${ }^{1-6}$ Sympathetic blockade decreases skin galvanic response with concomitant increases in blood flow $w^{1,3}$ and skin temperature. ${ }^{2,4-6}$ However, increases in skin temperature and blood flow during spinal anaesthesia have been measured mainly in the hand or foot. 1,2,4,5 Unanaesthetized areas undergo reflex vasoconstriction ${ }^{7,8}$ and a decrease in truncal skin temperature has been reported after spinal anaesthesia to a sensory blockade of $T_{10}$ or above. ${ }^{9}$ Therefore, the relationship between the extent of sympathetic blockade during spinal anaesthesia and changes in both skin blood flow and temperature in the anaesthetized area during spinal anaesthesia remains unexplained. 6,10

Total spinal anaesthesia (TSA) has been used for the treatment of intractable pain ${ }^{11-13}$ and as a method of general anaesthesia for abdominal surgery. ${ }^{14}$ Three patients were studied to ascertain whether regional skin temperature and blood flow are altered during extensive sympathetic blockade following TSA.

\section{Methods}

The study was approved by the Human Investigation Committee of Hokkaido University Hospital, and a written informed consent was obtained before the study. Three patients with intractable pain of different origins were studied. They had already received analgesics and nerve blocks (stellate ganglion block in patients \#2 and 3, thoracic epidural block in patient \#1); however, their complaints were not changed. Total spinal anaesthesia was indicated as a final treatment. The details of patients are summarized in Table $\mathrm{I}$. 
TABLE I Patient characteristics

\begin{tabular}{lllllll}
\hline $\begin{array}{l}\text { Patient } \\
\#\end{array}$ & Sex & $\begin{array}{l}\text { Age } \\
(y r)\end{array}$ & $\begin{array}{l}\text { Weight } \\
(\mathrm{kg})\end{array}$ & $\begin{array}{l}\text { Cause of } \\
\text { pain }\end{array}$ & $\begin{array}{l}\text { Area of } \\
\text { pain }\end{array}$ & $\begin{array}{l}\text { Anaesthetic } \\
\text { agent }(\mathrm{ml})\end{array}$ \\
\hline 1 & $\mathrm{~F}$ & 55 & 51 & $\begin{array}{l}\text { Whiplash } \\
\text { syndrome }\end{array}$ & $\mathrm{T}_{3-5}$ & $\begin{array}{l}1.5 \% \\
\text { lidacaine } \\
20 \mathrm{ml}\end{array}$ \\
2 & $\mathrm{M}$ & 45 & 60 & $\begin{array}{l}\text { Traumatic } \\
\text { headache }\end{array}$ & $\mathrm{C}_{2,3}$ & $\begin{array}{l}1.5 \% \\
\text { mepivacaine }\end{array}$ \\
& & & & & & $20 \mathrm{ml}$ \\
3 & $\mathrm{M}$ & 61 & 50 & $\begin{array}{l}\text { Postoperative } \\
\text { facial pain }\end{array}$ & $\mathrm{V}_{2,3}$ & $\begin{array}{l}1 \% \\
\text { lidocaine } \\
20 \mathrm{ml}\end{array}$ \\
\hline
\end{tabular}

TABLE II Haemodynamic variables

\begin{tabular}{|c|c|c|c|c|c|c|}
\hline \multirow{2}{*}{$\begin{array}{l}\text { Patient } \\
\#\end{array}$} & \multicolumn{2}{|c|}{ Control } & \multicolumn{2}{|c|}{$15 \min$ afier TSA } & \multicolumn{2}{|c|}{$30 \mathrm{~min}$ after TSA } \\
\hline & $H R$ & $A P$ & $H R$ & $A P$ & $H R$ & $A P$ \\
\hline 1 & 70 & $150 / 80$ & 73 & $108 / 58$ & 74 & $100 / 52$ \\
\hline 2 & 82 & $122 / 74$ & 84 & $98 / 54$ & 78 & $97 / 56$ \\
\hline 3 & 76 & $134 / 60$ & 80 & $70 / 35$ & 96 & $136 / 66$ \\
\hline
\end{tabular}

TSA, total spinal anaesthesia; HR, heart rate (bpm); AP, arterial pressure $(\mathbf{m m H g})$.

A fluid preload of 500-1000 $\mathrm{ml}$ was given before TSA which was scheduled in the morning. Lactated Ringer's solution, prewarmed to $37^{\circ} \mathrm{C}$, was infused in the left hand at a rate of $5 \mathrm{ml} \cdot \mathrm{kg}^{-1} \cdot \mathrm{hr}^{-1}$ in the operating room. The patients were placed on the operating table with the undressed right side of the body facing the thermography camera and they were allowed to adapt to the room temperature until skin temperature was constant. The ambient temperature in the operating room ranged from $25^{\circ} \mathrm{C}$ to $27^{\circ} \mathrm{C}$. Patients were not premedicated. The electroencephalogram, direct arterial pressure, ECG and respiratory pattern using chest impedance pneumography were monitored continuously during the procedures.

Skin temperature was measured at the right upper arm (over the deltoid muscle), at the right anterior chest at the nipple level, and at the right hand and foot, using infrared thermography (NEC San-ei,-6T66) with a sensitivity of $0.01^{\circ} \mathrm{C}$ between $24.2^{\circ} \mathrm{C}$ and $40.0^{\circ} \mathrm{C}$. Thermography was performed with a time constant of $0.2 \mathrm{sec}$ and a low pass filter under $12 \mathrm{kHz}$. A rectal thermo-probe (Terumo, MEPDK04I) was inserted after TSA.

Skin blood flow was measured with a laser Doppler flowmeter (Periflux, PF1d) at the right upper arm (C6 area). The analogue data outputs were recorded on FM tapes (TEAC, SR30) and off-line analysis was made using a signal processor (NEC San-ei, 7T18). It was updated every $50 \mathrm{msec}$ for one minute and the average blood flow

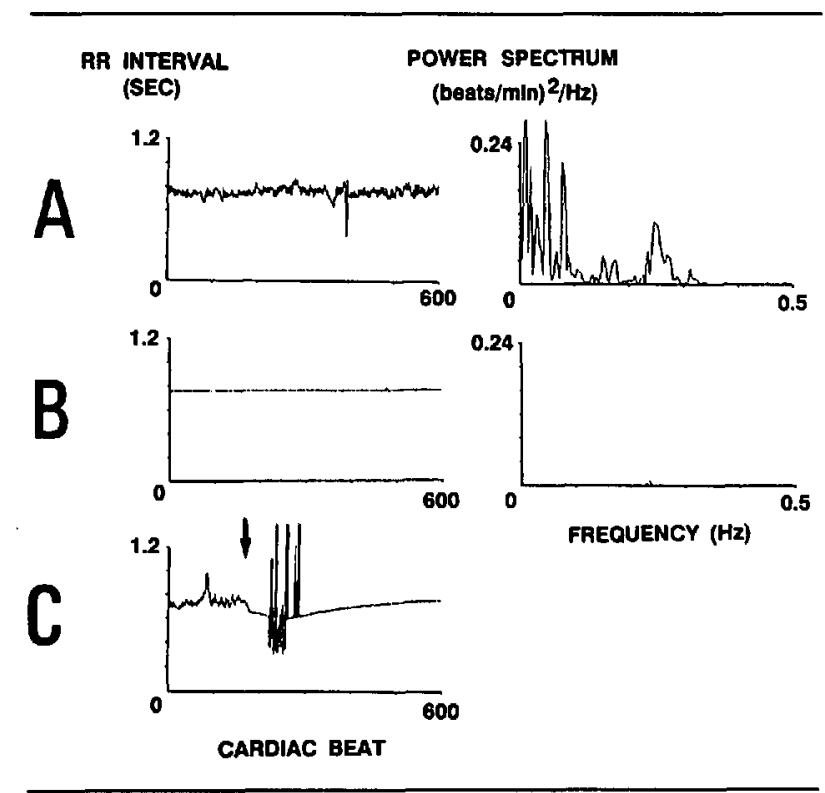

FIGURE 1 (A), (B) RR trendgraph and power spectrum of heart rate variation in patient \#3 before (A) and 15 minutes after (B) total spinal anaesthesia. (C) Change of RR interval during intrathecal administration of local anaesthetic agent in patient \#3. The arrow indicates the beginning of total spinal anaesthesia.

value (BFV), expressed as voltage change of signal output, was calculated. Differences in BFV were expressed as percent of the control level.

Spectral analysis of heart rate variations was performed to assess the magnitude of cardiac autonomic denervation. Consecutive $600 \mathrm{RR}$ intervals were measured with an accuracy of $1 \mathrm{msec}$ and displayed as a RR trendgraph on a computer display. Heart rate data were calculated every $0.5 \mathrm{sec}$ (a total of 512 times) by the method of integral pulse frequency modulation, which used a low-pass antialiasing digital filter with a cut-off frequency of 0.5 $\mathrm{Hz} .{ }^{15}$ Power spectrum density of these data was computed by using a fast Fourier transform. Total power was integrated between $0.04 \mathrm{~Hz}$ and $0.5 \mathrm{~Hz}$ and compared with the control value.

After obtaining all measurements, patients were placed in the left lateral position. A 23-gauge spinal needle was inserted into the $C_{7}-T_{1}$ subarachnoidal space, and $20 \mathrm{ml}$, $1-1.5 \%$ mepivacaine or lidocaine, were injected. Thiamylal sodium $3 \mathrm{mg} \cdot \mathrm{kg}^{-1}$ was given iv to avoid any uncomfortable sensation at the beginning of TSA. Then, patients were placed in the supine position with the left side of the body covered. The tracheas were intubated without muscle relaxants and the lungs were mechanically ventilated $\left(14 \mathrm{~min}^{-1}\right)$ with oxygen and air adjusted to maintain $\mathrm{PaCO}_{2} 35-45 \mathrm{mmHg}$ and $\mathrm{PaO}_{2}$ over $150 \mathrm{mmHg}$. The artificial nose (Engström, Edith) was used to warm and humidify the ventilator gases. 


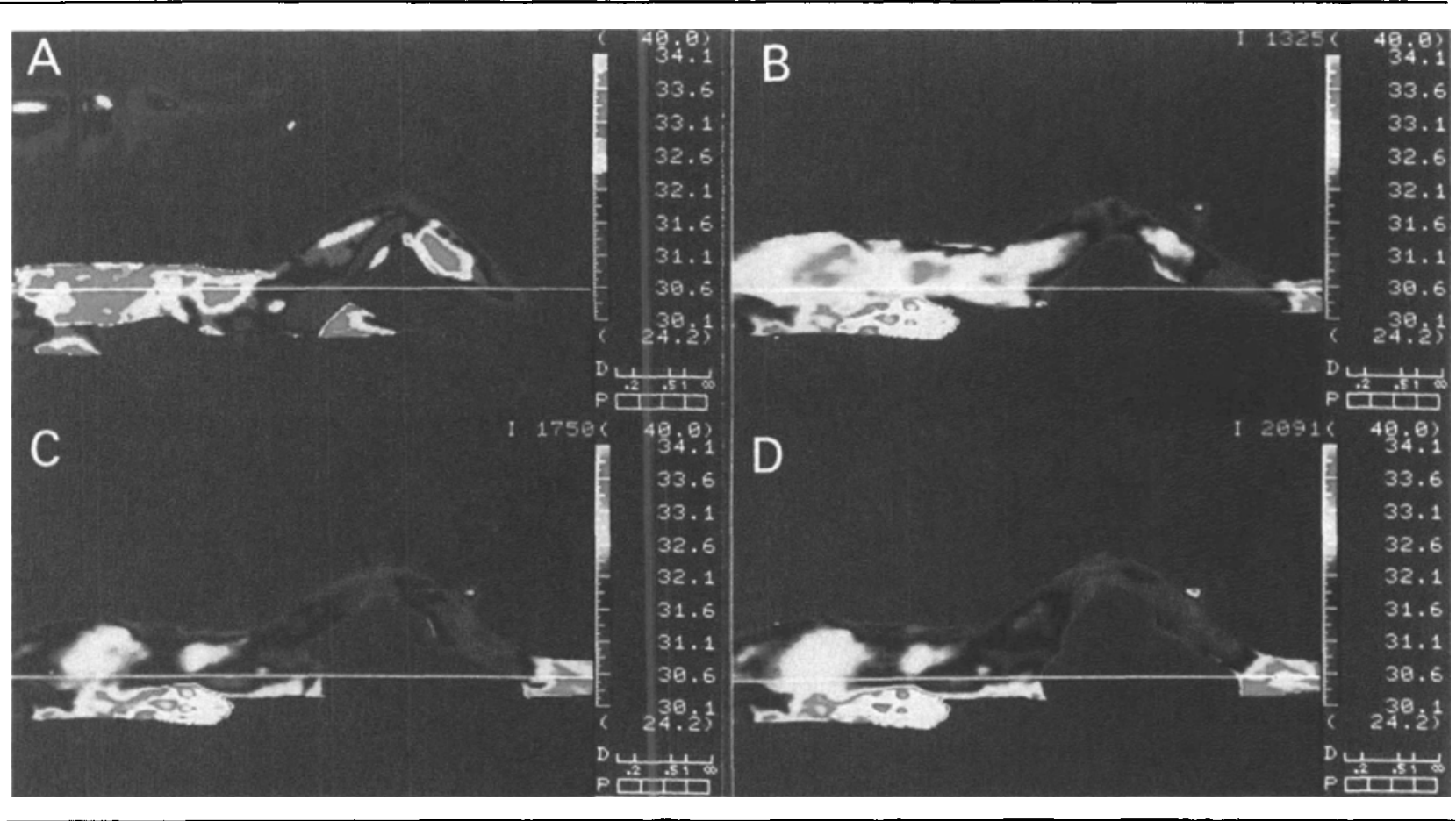

FIGURE 2 Thermographs in patient \#3 before (A) and 15 (B), 30 (C) and 45 (D) minutes after total spinal anaesthesia. The colour coded temperature scale is shown at right. Note marked elevations of temperature of hand and foot and decreases of temperature in truncal, arm and leg areas.

\section{Results}

Blood pressure decreased after TSA in three patients. Ephedrine, $5 \mathrm{mg}$, was administered iv to treat hypotension in patient \#3 after the measurement 15 mins after TSA. Heart rate did not change after TSA in the three patients, except at $30 \mathrm{~min}$ after TSA in patient \#3 after ephedrine administration (Table II).

Total spectral power of heart rate variation in each patient decreased to $1.1,1.0$ and $0.6 \%$ (Figure IA, IB), respectively. The $R R$ trendgraph during intrathecal administration of local anaesthetic agent in patient \#3 showed tachycardic changes initially, and a few minutes later RR interval returned to the control value (Figure IC), which is similar to the reaction of vagal denervation. ${ }^{16}$

The temperature of the truncal area including the arm and leg decreased following TSA by $1^{\circ} \mathrm{C}$, in contrast to the hand and foot where the temperature increased markedly by $3^{\circ} \mathrm{C}$ (Figure 2, Table III). The areas with increasing temperature were restricted to hand and foot, while temperatures in other areas decreased. Core temperature did not change.

A typical example of the change in peripheral blood flow 15 minutes after TSA in patient $\# 2$ is shown in Figure 3. Peripheral blood flow showed long-term cyclic vasomotor fluctuation with an approximate ten-second
TABLE III Temperature changes $\left({ }^{\circ} \mathrm{C}\right)$ in five different areas

\begin{tabular}{|c|c|c|c|}
\hline $\begin{array}{l}\text { Area and } \\
\text { patient \# }\end{array}$ & Control & $\begin{array}{l}\text { IS minutes } \\
\text { after TSA }\end{array}$ & $\begin{array}{l}30 \text { minuses } \\
\text { after TSA }\end{array}$ \\
\hline \multicolumn{4}{|c|}{ Upper arm } \\
\hline 1 & 34.3 & 33.0 & 31.8 \\
\hline 2 & 32.5 & 32.1 & 31.4 \\
\hline 3 & 33.4 & 32.7 & 32.3 \\
\hline \multicolumn{4}{|l|}{ Chest } \\
\hline 1 & 34.5 & 33.5 & 33.0 \\
\hline 2 & 33.1 & 32.3 & 31.4 \\
\hline 3 & 34.2 & 33.5 & 33.2 \\
\hline \multicolumn{4}{|l|}{ Hand } \\
\hline 1 & 31.0 & 34.5 & 34.5 \\
\hline 2 & 30.0 & 34.1 & 34.1 \\
\hline 3 & 31.5 & 33.5 & 34.5 \\
\hline \multicolumn{4}{|l|}{ Foot } \\
\hline 1 & 31.0 & 34.0 & 34.0 \\
\hline 2 & 30.0 & 33.6 & 33.6 \\
\hline 3 & 31.5 & 32.0 & 33.5 \\
\hline \multicolumn{4}{|l|}{ Rectum } \\
\hline 1 & not measured & 37.5 & 37.4 \\
\hline 2 & not measured & 36.3 & 36.5 \\
\hline 3 & not measured & 37.0 & 36.4 \\
\hline
\end{tabular}




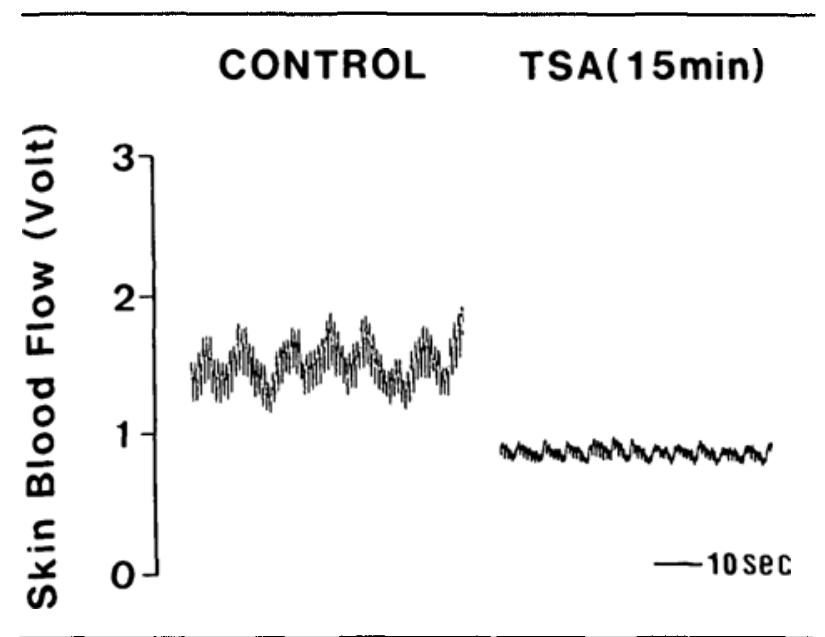

FIGURE 3 A typical recording of skin blood flow measured by laser Doppler flowmetry before (left panel) and $15 \mathrm{~min}$ after total spinal anaesthesia (TSA) (right panel) in patient \#2.

interval and short-term fluctuation concomitant with the pulse. The mean BFV for one minute in three patients decreased to $26.1,61.4,51.7 \%$ of the control value $15 \mathrm{~min}$ after TSA.

\section{Discussion}

Previous studies of skin temperature and blood flow changes during spinal anaesthesia in humans are conflicting because of the lack of information concerning areas in which sympathetic blockade occurred. ${ }^{6,10}$ The extent of sympathetic blockade following spinal or epidural anaesthesia revealed an unexpectedly higher level $\mathrm{l}^{6,17,18}$ or lower levels of anaesthesia. ${ }^{19}$ For this reason, we studied the effects of TSA which is thought to show extensive sympatho-vagal blockade. ${ }^{13}$

The most reliable evidence for the presence of sympathetic blockade is skin galvanic response, ${ }^{20-22}$ but this is not a quantitative measurement since it lacks definite diagnostic criteria of autonomic nervous system tone and there is baseline drift of skin galvanic potential during long periods of measurement. The skin galvanic response is inversely related to skin temperature. ${ }^{23}$ Vasomotor outflow in human cutaneous nerves is closely related to sudomotor outflow, ${ }^{24}$ which explains the good correlation between the skin galvanic response and blood flow. Therefore, we measured skin temperature and blood flow as indices of sympathetic nervous activity instead of using the skin galvanic response, although skin temperature and blood flow changes are indirect measurements of sympathetic activity.

Skin temperature depends to a great extent on blood flow, which is controlled by the sympathetic nervous system. The thermographic findings will depend, in part, on the functional integrity of sympathetic fibres, which are conveyed in the peripheral nerves to their destinations. Therefore, thermography has been widely used for the qualitative assessment of sympathetic blockade. $2,4,6,9$ Chamberlain et al. reported that the zone of differential sympathetic blockade averaged six or seven spinal segments using thermographic imagery. ${ }^{6}$ However, Peters observed a decrease in truncal skin temperature, while the skin temperatures in both the upper and lower limbs increased simultaneously during complete sympathetic blockade in dog. ${ }^{10}$ Bengtsson also described, using thermography, an increase of foot temperature and a decrease of trunk temperature following spinal anaesthesia. $^{9}$

The mechanisms of regional differences in skin blood flow and temperature during TSA can be explained as follows: spinal anaesthesia decreases sympathetic tone, causing opening of arteriovenous anastomoses since the hand and foot are rich in arteriovenous anastomoses which are mainly innervated by the sympathetic nervous system. ${ }^{25}$ Therefore, TSA opens these anastomoses as does spinal anaesthesia and consequently results in the increase of blood flow in the hand and foot. The decrease of truncal skin temperature is partly attributable to blockade of the cutaneous sympathetic postganglionic vasodilator neurons. ${ }^{26}$ Thus, blood distribution might shift to the more vasodilated areas (e.g., hand and foot) and blood flow in another area (the thorax and the various muscle regions) could decrease, depending on the magnitude of vasodilatation following TSA. ${ }^{8}$

Total spinal anesthesia blocks the vagus as well as the sympathetic nervous system ${ }^{13}$ and decreases heart rate variation, suggesting that neural control of the heart via the autonomic nervous system is abolished after TSA. Consequently, the balance between sympathetic and parasympathetic nervous activity might be preserved. Hence, heart rate, which reflects the net effect between sympathetic and parasympathetic nervous activities, was not altered (Figure 1B, Table II). However, a decrease in blood pressure arising from sympathetic blockade was observed in all patients since vagal blockade might not have an important role in blood pressure regulation.

Evidence for the presence of TSA was assured by several reasons. First, bilateral pupillary dilatation occurred promptly in all patients suggesting that the cervical cord was anaesthetized and that blockade of the autonomic innervation of the iris muscles and oculomotor region in the brainstem had occurred. Second, heart rate variation, a marker of autonomic nervous control of the heart, ${ }^{27}$ disappeared, which suggested the presence of thoracic sympathetic blockade as well as vagal blockade.

The extent of sympathetic nervous blockade cannot be assessed solely by the increases in skin blood flow and temperature especially in the truncal area of the patient 
whose sympathetic nervous system is extensively blocked by spinal anaesthesia. Our results indicate that sympathetic nervous blockade during spinal anaesthesia induces regional differences in skin blood flow and temperature.

\section{References}

1 Beene TK, Eggers GWN Jr. Use of the pulse monitor for determining sympathetic block of the arm. Anesthesiology $1974 ; 40 ; 412-4$.

2 Diaz $P M$. Use of liquid-crystal thermography to evaluate sympathetic blocks. Anesthesiology 1976; 44: 443-5.

3 Bengtsson M, Nilsson GE, Löfström JB. The effect of spinal analgesia on skin blood flow, evaluated by laser Doppler flowmetry. Acta Anaesthesiol Scand 1983: 27: 206-10.

4 McCollum PT, Spence VA, Macrae B, Walker WF. Quantitative assessment of the effectiveness of chemical lumbar sympathectomy. Br J Anaesth 1985; 57: 1146-9.

5 Benzon HT, Avram MJ. Temperature increases after complete sympathetic blockade. Regional Anesth 1986; 11: 27-30.

6 Chamberlain DP, Chamberlain BDL. Changes in the skin temperature of the trunk and their relationship to sympathetic blockade during spinal anesthesia. Anesthesiology 1986; 65: 139-43.

7 Bonica JJ, Berges $P U$, Morikawa $K$. Circulatory effects of peridural block: I. Effects of level of analgesia and dose of lidocaine. Anesthesiology 1970; 33: 619-26.

8 Arndt JO, Höck A, Stanton-Hicks M, Stühmeier KD. Peridural anesthesia and the distribution of blood in supine humans. Anesthesiology 1985; 63: 616-23.

9 Bengtsson $M$. Changes in skin blood flow and temperature during spinal analgesia evaluated by laser Doppler flowmetry and infrared thermography. Acta Anaesthesiol Scand $1984 ; 28$ : 625-30.

10 Peters $J$. Trunk skin temperature after sympathetic nerve block - Is the heat really on? Anesthesiology 1987; 66: 444-5.

11 Tsumura $Y$, Hoshiga $T$. Subarachnoidal injection therapy in chronic cases of the so-called whiplash syndrome. Acta Anaesthesiol Scand 1971; 15: 61-4.

12 Yamashiro H, Hirano $K$. Treatment with total spinal block of severe herpetic neuralgia accompanying median and ulnar nerve palsy. Masui 1987; 36: 971-5.

13 Goda Y, Kimura T, Goto Y, Kemmotsu O. Power spectral analysis of heart rate and peripheral blood flow variations during total spinal anesthesia. Masui 1989; 38: 1275-81.

14 Evans TI. Total spinal anaesthesia. Anaesth Intensive Care $1974 ; 2: 158-63$.

15 Rompelman $O$. The assesment of fluctuations in heartrate. In: Kitney RI, Rompelman O (Eds.). The Study of Heart-Rate Variability, 1st ed., Oxford: Clarendon Press, 1980: 59-77.
16 Applegate RJ, Hasser EM, Bishop VS. Vagal cold block in area postrema-lesioned dogs: interaction of vasopressin and sympathetic nervous system. Am J Physiol 1987; 252: H135-41.

17 Evans $J M$, Gauci $C A$, Watkins $G$. Horner's syndrome as a complication of lumbar epidural block. Anaesthesia 1975; 30: 774-7.

18 Mohan J, Potter JM. Pupillary constriction and ptosis following caudal epidural analgesia. Anaesthesia 1975; 30: 769-73.

19 Hopf HB, Weißbach B, Peters J. High thoracic segmental epidural anesthesia diminishes sympathetic outflow to the legs, despite restriction of sensory blockade to the upper thorax. Anesthesiology 1990; 73: 882-9.

20 Lader MH, Montagu JD. The psychogalvanic reflex: a pharmacological study of the peripheral mechanism. J Neurol Neurosurg Psychiat 1962; 25: 126-33.

21 Hagbarth KE, Hallin RG, Hongell A, Torebjork HE, Wallin BG. General characteristics of sympathetic activity in human skin nerves. Acta Physiol Scand 1972; 84: 164-76.

22 Knezevic W, Bajada S. Peripheral autonomic surface potential. A quantitative technique for recording sympathetic conduction in man. J Neurol Sci 1985; 67: 239-51.

23 Maulsby $R L$, Edelberg $R$. The interrelationship between the galvanic skin response, basal resistance, and temperature. J Comp Physiol Psychol 1960; 53: 475-9.

24 Bini $G$, Hagbarth $K E$, Hynninen $P$, Wallin BG. Thermoregulatory and rhythm-generating mechanisms governing the sudomotor and vasoconstrictor outflow in human cutaneous nerves. J Physiol 1980; 306: 537-52.

$25 \mathrm{Kim} \mathrm{JM}$, Reed $\mathrm{K} . \mathrm{PvO}_{2}$ changes in cutaneous veins during regression of spinal anaesthesia. Can J Anaesth 1987; 34: 358-61.

26 Gregor M, Jänig W, Riedel W. Response pattern of cutaneous postganglionic neurones to the hindlimb on spinal cord heating and cooling in the cat. Pflügers Arch 1976; 363: 135-40.

27 Akselrod S, Gordon D, Madwed JB, Snidman NC, Shannon $C$, Cohen $R J$. Hemodynamic regulation: investigation by spectral analysis. Am J Physiol 1985; 249; H867-75. 